\title{
Case Profile Analysis on Health- Care Associated Staphylococcal Infections and Community Acquired Sources: Demographic and Clinical Surveillance Study Ile - Ife South Western Nigeria
}

\author{
J. Omololu-Aso1 , A.O Oluduro1, Omololu-Aso 0.02 ; A.T \\ Owolabi ${ }^{3}$, Arwa Shesha ${ }^{4}$
}

\begin{abstract}
${ }^{1}$ Department of Microbiology, Obafemi Awolowo University, Ile- Ife, Nigeria
${ }^{2}$ Department of Obstetric and Gynaecology, University College Hospital, Ibadan. Nigeria.

${ }^{3}$ Department of Obstetric and Gynaecology, Obafemi Awolowo University, Ile- Ife, Nigeria.

${ }^{4}$ Dept. of Biology, North Carolina Agricultural and Technical, State University,1601 E. Market street,

Greensboro.NC 27411
\end{abstract}

\begin{abstract}
We looked into the frequent incidence of Staphylococcal infections among some clinical diagnosed infectious diseases reported cases at the Obafemi Awolowo University Teaching Hospital Complex, Ile - Ife, Nigeria and its community-based involvement. Eight hundred and fifty samples of different cultures were taken from hospital and community sources. The clinical sources were the routine specimens of wound swabs, urine, stool, blood and sputum from the Department of Microbiology and Parasitology laboratory of the Obafemi Awolowo University Teaching Hospitals Complex (OAUTHC) Ile-Ife. The non-clinical samples were obtained from the nasal cavity of apparently healthy food handlers at restaurants in Obafemi Awolowo University campus and food vendors in Ile-Ife central market. Samples were cultured on mannitol salt agar and incubated at $37^{\circ} \mathrm{C}$ for $24-48$ hours. Staphylococcus aureus were isolated and identified based on mannitol fermentation, Gram's reaction, positive results for catalase, coagulase and DNAse tests. The data generated were subjected to statistical analysis using TTest. Two hundred and thirty $(56.8 \%)$ of $S$. aureus isolates were recovered from the hospital sources and 175 (43.2\%) from the community setting. Incidence rate was the highest in age range 21-30 among urine, wound, sputum and blood Case -based samples analyzed. Urine S. aureus Case-based infection in female (58.6\%) was higher than (41.4\%) in male, Sexually Transmitted Disease (STD) reported cases was about more than doubled of other infections follow by the urinary tract (UTI) independent infection. Wound associated case- based infections among Female $(65.5 \%)$ was doubled that of Male which was $(34.3 \%)$ and sepsis independent cases constituted $32.8 \%$; Sputum based S. aureus infection in female was $56.8 \%$ higher than $43.2 \%$ in Male. $66.7 \%$ from Pulmonary Inflammation Case- based investigated constituted overwhelmingly more than double of other infections. In addition, (63.8\%) Stool associated Case-based infections from Female was higher than 36.2\% observed among Male. Diarrhea cases constituted majorly of $38.3 \%$ and it showed an exceptional incident rate of infections which was noticed to be higher among the age range 11-20. Blood S. aureus associated infections in female (53.3\%) was higher than $46.7 \%$ in Male and bacteremia/ sepsis cases predominated about $63.3 \%$. ( $\mathrm{T}=95 \%$ confidence interval of the difference). Community S. aureus isolates accounted for $43 \%$ of the total isolates from which cell phones and food handlers constituted $15 \%$, and stethoscopes S. aureus isolates $13 \%$. The carrier rate of S. aureus in the nose of apparently healthy individuals among the food handlers in the community was higher among Male (64.5\%) than $35.5 \%$ Female. ( $\mathrm{T}=95 \%$ confidence interval of the difference). Plan are underway to evaluate the relationship between antibiotics use in this hospital and the pattern of antimicrobial resistance observed.
\end{abstract}

Keywords: Staphyloccoccal infection, Hospital, Community, Case -based profile.

Introduction

Staphylococcus aureus had been isolated from

several clinical specimens from Nigeria (Esan et al., 2009). In 2003-2004, approximately 29\% (78.9

This article is published under the terms of the Creative Commons Attribution License 4.0 Author(s) retain the copyright of this article. Publication rights with Alkhaer Publications.

Published at: http://www.ijsciences.com/pub/issue/2016-07/

DOI: 10.18483/ijSci.841; Online ISSN: 2305-3925; Print ISSN: 2410-4477 
million persons) and $1.5 \%$ (4.1 million persons) of the US population was colonized in the nose with $S$. aureus and Methicillin Resistant Staphylococcus aureus (MRSA) respectively (Gorwitz et al., 2008). Over the past several decades, $S$. aureus has been a leading cause of hospital acquired infections (Lowy, 1998). It is also associated with wound sepsis, osteomyelitis and post surgical toxic shock syndrome with substantial rates of mobidity and mortality (Shopsin et al., 2001; Engemann et al., 2003). Methicillin- resistant $S$. aureus infections have become a common problem in the community acquired infections, and has also been associated with prolonged hospital stay and increased costs ( Kopp et al., 2004; Lodise and Mckinnon, 2005; Nixon et al., 2006).

In 2005, there was an estimated 478,000 hospitalization with a diagnosis of $S$. aureus infection in US hospitals, and of these, approximately 278,000 hospitalizations were related to MRSA. These include, people admitted to the hospital for treatment of an infection that was acquired or occurred outside the hospital. (Klein et al., 2007). In hospitals, the proportion of healthcare associated staphylococcal infections that are due to MRSA has been increasing and $2 \%$ of $S$. aureus infections in US intensive care units were MRSA in 1974, $22 \%$ in 1995 , and $64 \%$ in 2004 (Klevin et al., 2006). One of the reasons for the success of this human pathogen is its great variability in occurring at different periods and places with diverse clonal types and antibiotic resistance patterns within region and countries. 'Infections caused by antibiotic- resistant $S$. aureus bring about serious problem in the general population, such infections can be particularly devastating for the very young, the elderly and the immunocompromised (American Society of Microbiology, 2007). Staphylococcus aureus strains colonise and establish infection in a wide range of body sites, including the blood, indwelling biomaterials, mucosa surfaces, bone, and other tissues. The mechanisms underlying the tropism of $S$. aureus for specific infection sites are unclear, associations have been demonstrated between the disease type, the pattern of toxin genes, and the genetic backgrounds of particular $S$. aureus strains (Jarraud et al., 2002). For example, a correlation has been found between unrelated cases of $S$. aureus infection and a single subset of strains, such as a clone producing TSST-1 responsible for most epidemiologically unrelated cases of urogenital toxic shock syndrome (Musser et al., 1990), a clone producing Panton Valentine Leukocidin $(P V L)$ and causing neurotic pneumonia (Gillet et al.,2002), and clones producing Toxic Shock Syndrome Type 1 and enterotoxin $\mathrm{C}$ in neonatal toxic shock syndrome-like exanthematous disease (Kikuchi, 2003).

Patients and individuals that are at high risk of developing Staphylococcal infections include surgical patients, the ederly, neonates, diabetic patients and patients with chronic illness (Huda et al., 2011) and immune-compromised patients such as cancer and HIV/AIDS patients others include patients with indwelling devices such as catheters, trauma, burn patients and kidney dialysis patients (Klevens et al., 2007). S. aureus infections can be spread through contact with pus from an infected wound, skin to skin contact with an infected person by producing hyaluronidase that destroys tissues, and contact with objects such as towels, bed sheets, clothing, or athletic equipments used by an infected person. Deeply penetrating $S$. aureus infection can be severe. Prosthetic joints put a person at particular risk for septic arthritis, and staphylococcal endocarditis and pneumonia (Huda et al., 2011).

This study marked the cooperative effort for surveillance among health- care institution, academia and Ile -Ife central community and was designed to isolate and identify $S$. aureus in samples stocks of various patients' with related case histories in Academic Teaching Hospital sources viz, clinical ; (stool, blood, urine, sputum, wound), and nonclinical, viz food handlers and cell phones and doctors' stethoscope. Univariate analysis of correlated variables was done with T-test Statistical Significance.

\section{Materials and Methods \\ Source of bacterial isolates}

Staphylococcus aureus isolates were recovered from both clinical and non-clinical specimens. The clinical sources were from the routine specimens of wound swabs, urine, stool, and sputum of different diagnosed patients' samples submitted to the Microbiology laboratory of the Obafemi Awolowo University Teaching Hospital Complex (OAUTHC), (Urban Centre), Ile - Ife. The non-clinical isolates were recovered as nasal swabs from food handlers at the Obafemi Awolowo University (OAU) campus restaurants, marketers at the Ile-Ife central market and also from fomites within the hospital, which comprised of doctors stethoscopes, and cell phones from the community dwellers and the Health care workers.

\section{Samples collection}

Samples were collected between the period of October 2007 and November 2009. Eight hundred and fifty (850) swab samples from clinical and nonclinical sources at Obafemi Awolowo University Teaching Hospital Complex; OAU Campus community and Ile-Ife environs were obtained. Sterile cotton-tipped applicators (Sterilin, England) appropriately moistened with sterile distilled water were used for swabbing sample surfaces. 
Samples from both hospital ( hospitalized patients who were on different types of antibiotic treatment) and the community with different sexes, age ranges and of different diagnostic infections histories ranging from diabetic ulcers, cancers (breast cancer, prostrate carcinoma) obstructive uropathy, (e.g benign prostrate hypertrophy $(\mathrm{BPH})$ ) septicaemia, urinary tract infection, burnt injuries, gastroenteritis, pelvic inflammatory diseases, sexually transmitted infections, pneumonia and many other clinical diagnosis cases were considered.

The non-clinical samples were obtained from the nostrils of apparently healthy community food handlers, also from cell phones and stethoscopes. The swabs after collection were taken to the laboratory immediately for bacteriological analysis.

\section{Microbiological analysis}

Isolation of $S$. aureus was done by standard procedure in which the samples were inoculated on freshly prepared mannitol salt agar plates (Oxoid, Basingstoke, Hampshire, England) and incubated at $37^{\circ} \mathrm{C}$ for $24 \mathrm{~h}$. Golden yellow colonies on Mannitol Salt agar (MSA) after the incubation period were taken presumptively for $S$. aureus.

\section{Phenotypic and biochemical identification of the isolates}

The isolates were Gram stained as described by Olutiola et al. (1991). Biochemical identification of the isolates was carried out using standard methods The following biochemical tests were carried out on the isolates namely catalase, tube coagulase test, and the DNase test using DNase agar based (Oxoid Ltd., Basingstoke, Hampshire, England). The confirmed isolates were stored as stock culture on nutrient agar slants and kept at about $4^{\circ} \mathrm{C}$ until further use.

\section{Gram's reaction Test}

Gram staining technique is a differential staining procedure that separate bacteria into two classes i.e Gram positive and Gram negative. A smear of an 18-24 hour old cuture on nutrient agar was prepared on a clean microscopic slides. The smear was then heat-fixed by passing the slide through a bursen burner flame. The smear was flooded with crystal violet and allowed to react for 1 minute after which the stained was poured of and the smear rinsed under gentle running tap water. Thereafter, the slide was flooded with Gram's iodine solution ( a mordant) and then rinsed off under gentle running tap water. The smear was later decolorized with $95 \%$ ethanol, rinsed under gentle running tap water, and counterstained with safranin for about 30 seconds. The slide was then washed under gentle running tap, allowed to air dried and then examined under the oil immersion objective of the light compound microscope (Leica Gallen 111; Leica Inc, NY, USA). Gram positive staphylococci appeared as round clustered and purple in color.

\section{Catalase test}

This test was used to differentiate between staphylococci (catalase positive) and streptococci (catalase negative). Catalase positive bacteria are capable of producing an enzyme known as catalase which breaks down hydrogen peroxide to water and two drops of $3 \%$ hydrogen peroxide was placed on a clean grease-free slide. Colonies of the isolate similar to Gram positive cocci in clusters was emulsified in the drop. Rapid effervescence of gas was recorded as positive. A control slide containing only drop of hydrogen peroxide showed no gas bubbles.

\section{Coagulase test}

The isolates were inoculated into $1 \mathrm{ml}$ of nutrient broth in test tubes and incubated overnight at $37^{\circ} \mathrm{C}$. One milliliter of fresh human plasma was added into the tubes previously incubated with the isolates and further incubated at $37^{\circ} \mathrm{C}$ and were examined at intervals for 4 hours. Formation of clot up to $4 \mathrm{hr}$ at $37{ }^{\circ} \mathrm{C}$ indicates positive coagulation (Olutiola et al., 1991). ATCC25923 serves as control strain.

\section{DNase test}

This is a confirmatory test for $S$. aureus based on its ability to produce DNase enzyme that can degrade nucleic acids. Thirty nine grams of the agar was suspended in 1 litre of distilled water and dissolved completely by boiling. The content was sterilized by autoclaving at $121^{\circ} \mathrm{C}$ for 15 minutes. The plates were inoculated by spotting the bacterial culture onto the surface of the agar so that a thick plaque of growth became evident after 18 hours incubation. The plates were flooded with $1 \mathrm{~N} \mathrm{HCl}$ and allowed to stand for 2 minutes. The clear zones around the colonies were taken as positive result for the growth of $S$. aureus.

Staphylococcus aureus ATCC25923 and S. epidermidis served as positive and negative control.

\section{Results and Discussion}

\section{Staphylococccus aureus isolates}

A total of $405 \mathrm{~S}$. aureus isolates were obtained from the 721 staphylococci recovered from 850 samples collected from clinical and non-clinical sources. The clinical isolates comprised of $230(57 \%)$ and 175 (43\%), non - clinical. clinical isolates were sourced as follows; wounds (58); stools (47) ; urine (58) ; sputum (37) and blood (30), (Table 1).

The highest rate of isolation of $S$. aureus isolates from clinical sources was from wounds $(14.3 \%)$ and stools samples (14.3\%), while cell phones $15 \%$ and food handlers $(15 \%)$ constituted the highest among non - clinical $S$. aureus isolates. Overall, the 
prevalence of $S$. aureus isolates recovered from clinical sources are of statistical different $(\mathrm{T}=0.141)$.

Table 2 shows the colonial morphology and biochemical identification of $S$. aureus isolates from clinical and non-clinical sources. The observation of golden yellow colouration showed fermentation of the mannitol salt agar by the Staphylococcus sp. The isolates appeared purple coloration with Gram stain (Gram positive cocci). Rapid effervescence of gas recorded showed positive catalase reaction coupled with positive tube coagulases. All the $405 \mathrm{~S}$. aureus were DNase positive.

Table 1: Distribution of $S$. aureus isolates in the sample sources.

\begin{tabular}{|c|c|}
\hline Clinical Sources. & Nos of $S$. aureus isolated \\
\hline Urine $\mathrm{n}=100$ & $58(14.3 \%)$ \\
\hline Wound $n=100$ & $58(14.3 \%)$ \\
\hline Stool $n=100$ & $47(11.6 \%)$ \\
\hline Sputum $n=100$ & $37(9.1 \%)$ \\
\hline Blood $n=70$ & $30(7.4 \%)$ \\
\hline TOTAL & 230 \\
\hline MEAN & $11.4 \% \pm 7.8$ \\
\hline \multicolumn{2}{|l|}{ Non-clinical Sources } \\
\hline Cell phone $\mathrm{n}=100$ & $62(15.3 \%)$ \\
\hline Stethoscopes $n=51$ & $51(12.6 \%)$ \\
\hline Food handlers. $n=100$ & $62(15.3 \%)$ \\
\hline Total & 175 \\
\hline Sum total 405 & $14.333 \pm 1.333$ \\
\hline
\end{tabular}

Table 2: Colonial morphology and biochemical identification of S. aureus isolates

\begin{tabular}{ll}
\hline $\begin{array}{l}\text { Colonial } \\
\text { Morphology }\end{array}$ & Characteristics. \\
& \\
\hline Growth on Nutrient agar & Raised, Smooth, serrate, opaque \\
Growth on Mannitol salt agar & Ferment mannitol golden yellow coloration \\
Gram reaction & Positive cocci \\
Catalase Test. & Positive \\
Coagulase Test & Positive. \\
DNase & Positive \\
\hline
\end{tabular}

The frequency of urine $S$. aureus infections in relation to the age range and sex is presented in Table 3 Fifty eight samples were confirmed of $S$. aureus infections of which $24(41.4 \%)$ were males and 34 $(58.6 \%)$ were females.

Table 4 shows the distribution of $S$. aureus in the urine samples of patients with their case histories. The various $S$. aureus infections occurred as follows: Sexually Transmitted Disease cases which constituted overwhelmingly $25(43.1 \%)$ followed by Urinary Tract Infection cases $15(25.7 \%)$; Pelvic inflammatory disease cases $7(12.1 \%)$; Beningn prostatic hypertrophy $6(10.3 \%)$; both cancer of prostate gland and chronic renal failure cases constituted $2(3.4 \%)$ and $1(1.7 \%)$ respectively.

The distribution of wound infections in relation to age and sex is shown in Table 5. Fifty eight (58) patients' samples were confirmed of $S$. aureus infections of which $20(34.5 \%)$ were male and 38 $(65.5 \%)$ were female.

Table 6 shows the distribution of wound S. aureus among individual case histories of the wound samples collected. The various $S$. aureus infections occurred as follows: Septicaemia cases which constituted overwhelmingly $32.8 \%$ followed by Burnt injury cases, $24.1 \%$; 
Table 3. Distribution of urine infections in relation to age and sex.

\begin{tabular}{llll}
\hline Age range & $\begin{array}{l}\text { Total } \\
\text { number } \\
\text { of patient } \\
\text { samples }\end{array}$ & $\begin{array}{l}\text { No. } \\
\text { Prevalence } \\
\text { Male } \\
(\boldsymbol{\%})\end{array}$ & $\begin{array}{l}\text { Female } \\
(\%)\end{array}$ \\
\hline $\mathbf{1 1 - 2 0}$ & 5 & $2(40.0 \%)$ & $3(60 \%)$ \\
$\mathbf{2 1 - 3 0}$ & 16 & $5(31.25)$ & $11(68.75 \%)$ \\
$\mathbf{3 1 - 4 0}$ & 12 & $6(50 \%)$ & $6(50.0 \%)$ \\
$\mathbf{4 1 - 5 0}$ & 14 & $4(28.57)$ & $10(71.43 \%)$ \\
$\mathbf{5 1 - 6 0}$ & 7 & $5(71.43 \%)$ & $2(28.57 \%)$ \\
$\mathbf{6 1 - 7 0}$ & 4 & $2(50.0 \%)$ & $2(50.00 \%)$ \\
& $\mathrm{t}-0.7476=$ & & \\
Total & 0.4883 & $\mathbf{2 4}(\mathbf{4 1 . 4 \% )}$ & $\mathbf{3 4}(\mathbf{5 8 . 6 \% )}$ \\
& $\mathbf{5 8}$ & $\mathbf{4 5 . 2 8}$ & $\mathbf{5 4 . 7 9}$ \\
& Median & & \\
\hline
\end{tabular}

Table 4: Distribution of Urine $S$. aureus case histories

\begin{tabular}{ll}
\hline $\begin{array}{l}\text { Case histories/ Urine } \\
\text { S. aureus infections }\end{array}$ & $\begin{array}{l}\text { Total number } \\
(\boldsymbol{\%} .)\end{array}$ \\
\hline & \\
STD & $25(43.1)$ \\
UTI & $15(25.7 \%)$ \\
BPH & $6(10.3 \%)$ \\
CAP & $2(3.4 \%)$ \\
PID & $7(12.1 \%)$ \\
U & $2(3.4 \%)$ \\
CRF & $1(17.0 \%)$ \\
TOTAL & $\mathbf{5 8}$ \\
\hline
\end{tabular}

STD: Sexually Transmitted Diseases; UTI: Urinary Tract Infection; CAP: Cancer of prostate Gland, BPH: Benign Prostatic Hypertrophy, PID ; Pelvic Inflammatory Diseases, U:Urethritis, CRF: Chronic renal failure.

Table 5. Distribution of wound infections in relation to age and sex

\begin{tabular}{llll}
\hline Age range & $\begin{array}{l}\text { Total number } \\
\text { of patients } \\
\text { Samples }\end{array}$ & $\begin{array}{l}\text { No. \% Prevalence } \\
\text { Male } \\
(\mathbf{\%})\end{array}$ & $\begin{array}{l}\text { Female } \\
(\boldsymbol{\%})\end{array}$ \\
\hline $\mathbf{1 1 - 2 0}$ & 10 & $5(50.0 \%)$ & $5(50 \%)$ \\
$\mathbf{2 1 - 3 0}$ & 21 & $6(28.5 \%)$ & $15(71.43 \%)$ \\
$\mathbf{3 1 - 4 0}$ & 6 & $1(16.67 \%)$ & $5(83.33 \%)$ \\
$\mathbf{4 1 - 5 0}$ & 12 & $5(41.67)$ & $7(58.33 \%)$ \\
$\mathbf{5 1 - 6 0}$ & 8 & $5(25.00 \%)$ & $6(75.00 \%)$ \\
$\mathbf{6 1 - 7 0}$ & 1 & $1(100 \%)$ & $(0 \%)$ \\
& & & $\mathbf{T = 5 4 . 8 2 9 2}$ \\
Total & $\mathbf{5 8}$ & $\mathbf{2 0}(\mathbf{3 4 . 5 \%})$ & $\mathbf{3 8}(\mathbf{6 5 . 5 \%})$ \\
& & $\mathbf{X = 4 7 . 0 1 8}$ & $\mathbf{X = 4 9 . 7 3}$ \\
\hline
\end{tabular}


Table 6: Distribution of Wound $S$. aureus case histories

\begin{tabular}{ll}
\hline $\begin{array}{l}\text { Case histories/ Wound } \\
\text { S. aureus infections }\end{array}$ & $\begin{array}{l}\text { Total number } \\
(\boldsymbol{\%} .)\end{array}$ \\
\hline & \\
BI & $14(24.1)$ \\
ISI & $4(6.9 \%)$ \\
DF & $6(10.3 \%)$ \\
B & $2(3.4 \%)$ \\
VLU & $3(5.2 \%)$ \\
AB & $2(3.4 \%)$ \\
TEN & $8(13.8 \%)$ \\
Sep & $19(32.8 \%)$ \\
TOTAL & $\mathbf{5 8}$ \\
\hline
\end{tabular}

BI: Burnt Injuries; Sep: Septicaemia; ISI; Infected Surgical Implant. DF: Diabetic foot; B: Boil, VLU: Venous leg ulcer; AB: Abscess. TEN: Toxic epidermal necrosis.

Table 7 shows the frequency of sputum S. aureus infections according to the age range and sex of individual sources of the sputum samples. Thirty seven, patients' samples were confirmed of $S$. aureus infections of which $16(43.2 \%)$ were male and $21(56.8 \%)$ were female.

Table 8 shows the distribution of sputum S. aureus among individual case histories of the sputum samples collected. The various $S$. aureus infections occurred as follows: pneumonia cases which constituted overwhelmingly $24(64.9 \%)$ followed by bronchitis cases, 11(29.7\%); Mycobacterium tuberculosis cases and HIV each constituted 1(2.7\%) only.

Table 9 shows the frequency of stool $S$. aureus infections according to the age range and sex of individual sources of the stool samples. Forty seven, patients' samples were confirmed infected with $S$. aureus and of which $17(36.2 \%)$ were male and $30(63.8 \%)$ were female.

Table 10 shows the distribution of stool S. aureus among individual case histories of the stool samples collected. The various $S$. aureus infections occurred as follows: diarrhoea cases which constituted $18(38.3 \%)$ followed by amoeboid dysentary cases, $15(31.9 \%)$; gastroenteritis cases, $11(23.4 \%)$ and cholera, 3(6.4\%).

Table 11 shows the frequency of blood $S$. aureus infections according to the age range and sex of individual sources of the blood samples. Thirty patients' samples were confirmed of $S$. aureus infections of which $14(46.7 \%)$ were male and $53.3 \%$ were female.

Table 7. Distribution of sputum infections in relation to age and sex

\begin{tabular}{llll}
\hline Age range & $\begin{array}{l}\text { Total number } \\
\text { of patients } \\
\text { samples }\end{array}$ & $\begin{array}{l}\text { No. \% Prevalence } \\
\text { Male } \\
(\boldsymbol{\%})\end{array}$ & $\begin{array}{l}\text { Female } \\
(\boldsymbol{\%})\end{array}$ \\
\hline $\mathbf{1 1 - 2 0}$ & 3 & $1(33.33 \%)$ & $2(66.67 \%)$ \\
$\mathbf{2 1 - 3 0}$ & 15 & $5(33.33 \%)$ & $10(66.67 \%)$ \\
$\mathbf{3 1 - 4 0}$ & 5 & $3(60 \%)$ & $2(40.0 \%)$ \\
$\mathbf{4 1 - 5 0}$ & 6 & $5(83.33 \%)$ & $1(16.67 \%)$ \\
$\mathbf{5 1 - 6 0}$ & 3 & $1(33.33 \%)$ & $2(66.67 \%)$ \\
$\mathbf{6 1 - 7 0}$ & 5 & $1(20.0 \%)$ & $4(80.00 \%)$ \\
& & $\mathbf{T = 3 . 8 4 7 8}$ & $\mathbf{T = 4 . 0 6 2 9 2}$ \\
Total & $\mathbf{3 7}$ & $\mathbf{1 6}(\mathbf{4 3 . 2 \%})$ & $\mathbf{2 1}(\mathbf{5 6 . 8 \%})$ \\
& & $\mathbf{X = 4 8 . 0 1 8}$ & $\mathbf{X = 5 0 . 7 3 0 3}$ \\
\hline
\end{tabular}


Table 8: Distribution of Sputum S.aureus infection case histories

\begin{tabular}{ll}
\hline $\begin{array}{l}\text { Case histories/ Sputum } \\
\text { S. aureus infections }\end{array}$ & $\begin{array}{l}\text { Total number } \\
(\%)\end{array}$ \\
\hline & \\
HIV/AIDS & $1(2.7 \%)$ \\
PN & $24(64.9 \%)$ \\
TB & $1(2.7 \%)$ \\
CB & $11(29.7 \%)$ \\
Total & $\mathbf{3 7}$ \\
\hline
\end{tabular}

HIV = Human Immunodeficiecy virus/ Aquired Immune Deficiency Syndrome.

$\mathbf{P N}=$ Pneumonia.

TB $=$ Tuberculosis

$\mathbf{C B}=$ Chronic bronchitis

Table 9. Distribution of Stool infections in relation to age and sex

\begin{tabular}{llll}
\hline Age range & $\begin{array}{l}\text { Total number } \\
\text { of patients } \\
\text { samples }\end{array}$ & $\begin{array}{l}\text { No.\%Prevalence } \\
\text { Male (\%) }\end{array}$ & Female (\%) \\
\hline $\mathbf{1 1 - 2 0}$ & 10 & $3(30.0 \%)$ & $7(70.0 \%)$ \\
$\mathbf{2 1 - 3 0}$ & 14 & $7(50.0 \%)$ & $7(50.0 \%)$ \\
$\mathbf{3 1 - 4 0}$ & 8 & $1(12.5 \%)$ & $7(87.5 \%)$ \\
$\mathbf{4 1 - 5 0}$ & 6 & $3(50.0 \%)$ & $3(50.0 \%)$ \\
$\mathbf{5 1 - 6 0}$ & 6 & $1(16.7 \%)$ & $5(83.3 \%)$ \\
$\mathbf{6 1 - 7 0}$ & 3 & $2(66.7 \%)$ & $1(33.3 \%)$ \\
& & $\mathbf{T = 3 . 8 4 7 8 0}$ & $\mathbf{T = 4 . 0 6 2 9 2}$ \\
Total & $\mathbf{4 7}$ & $\mathbf{1 7}(\mathbf{3 6 . 2 \%})$ & $\mathbf{3 0}(\mathbf{6 3 . 8 \%})$ \\
& & $\mathbf{X = 4 8 . 0 1 8}$ & $\mathbf{X = 5 0 . 7}$ \\
\hline
\end{tabular}

Table 10: Distribution of Stool S.aureus infection Case histories

\section{Case histories/ Stool}

S. aureus infections

\section{Total number}

$(\%)$

$\begin{array}{ll}\text { Gts } & 11(23.4 \%) \\ \text { Dia } & 18(38.3 \%) \\ \text { AD } & 15(31.9 \%) \\ \text { C } & 3(6.4 \%) \\ \text { Total } & 47\end{array}$

Gts = Gastroenteritis

Dia $=$ Diarrhoea

$\mathbf{A D}=$ Amoeboid dysentery

$\mathbf{C}=$ Cholera 
Table 11. Distribution of Blood infections in relation to age and sex

\begin{tabular}{llll}
\hline Age range & $\begin{array}{l}\text { Total number } \\
\text { of patients } \\
\text { samples }\end{array}$ & $\begin{array}{l}\text { No \% Prevalence } \\
\text { Male } \\
(\boldsymbol{\%})\end{array}$ & Female $(\boldsymbol{\%})$ \\
\hline $\mathbf{1 1 - 2 0}$ & 4 & $2(50.0 \%)$ & $2(50.0 \%)$ \\
$\mathbf{2 1 - 3 0}$ & 8 & $3(37.5 \%)$ & $5(62.5 \%)$ \\
$\mathbf{3 1 - 4 0}$ & 3 & $2(66.7 \%)$ & $1(33.3 \%)$ \\
$\mathbf{4 1 - 5 0}$ & 8 & $4(50.0 \%)$ & $4(50.0 \%)$ \\
$\mathbf{5 1 - 6 0}$ & 3 & $1(33.3 \%)$ & $2(66.7 \%)$ \\
$\mathbf{6 1 - 7 0}$ & 3 & $1(33.3 \%)$ & $2(66.7 \%)$ \\
& & & \\
$\mathbf{7 1 - 8 1}$ & 1 & $1(100 \%)$ & $0 \%$ \\
& & $\mathbf{T = 3 . 8 4 7 8 0}$ & $\mathbf{T = 4 . 0 6 2 9 2}$ \\
Total & & $\mathbf{1 4}(\mathbf{4 6 . 7 \%})$ & $\mathbf{1 6}(\mathbf{5 3 . 3 \%})$ \\
& $\mathbf{3 0}$ & $\mathbf{X = 4 8 . 0 1 7 8}$ & $\mathbf{X = 5 0 . 7 3 0 3}$ \\
\hline
\end{tabular}

Table 12: Distribution of Blood S. aureus infection Case Histories.

\begin{tabular}{ll}
\hline Case histories/ Blood & Total number \\
S. aureus infections & $\%$. \\
\hline
\end{tabular}

$\begin{array}{ll}\text { B } & 19(63.3 \%) \\ \text { PC } & 1(3.3 \%) \\ \text { CML } & 3(10.0 \%) \\ \text { MM } & 7(23.3 \%) \\ \text { Total } & \mathbf{3 0}\end{array}$

PC: Postrate cancer.; CML: Chronic myeloma leukemia,; MM:Multiple myeloma

B: Bacteremia.

Table 13. Distribution of Food handlers nasal swabbed samples in relation to age and sex

\begin{tabular}{llll}
\hline Age range & $\begin{array}{l}\text { Total number } \\
\text { of nasal swabbed } \\
\text { samples }\end{array}$ & $\begin{array}{l}\text { Number of } \\
\text { Male } \\
(\%)\end{array}$ & $\begin{array}{l}\text { Number of } \\
\text { Female } \\
(\%)\end{array}$ \\
\hline $\mathbf{1 1 - 2 0}$ & 12 & $11(91.67 \%)$ & $1(8.33 \%)$ \\
$\mathbf{2 1 - 3 0}$ & 19 & $12(63.16 \%)$ & $7(36.84 \%)$ \\
$\mathbf{3 1 - 4 0}$ & 19 & $9(47.37 \%)$ & $10(52.63 \%)$ \\
$\mathbf{4 1 - 5 0}$ & 6 & $5(83.33 \%)$ & $1(16.67 \%)$ \\
$\mathbf{5 1 - 6 0}$ & 6 & $3(50.0 \%)$ & $3(50.0 \%)$ \\
Total & $\mathbf{6 2}$ & $\mathbf{4 0}(\mathbf{6 4 . 5 \% )}$ & $\mathbf{2 2}(\mathbf{3 5 . 5 \% )}$ \\
\hline
\end{tabular}

Table 12, Shows the distribution of blood $S$. aureus among individual case histories of the blood samples collected. The various $S$. aureus infections occurred as follows: bacteremia cases which constituted overwhelmingly $19(63.3 \%)$ followed by multiple myeloma cases, 9(23.3\%) ; chronic myelomic leukemia , 3(10.0\%) and prostate cancer only $1(3.3 \%)$.

Table 13: Shows the frequency of food handlers nasal swabbed $S$. aureus according to the age range and sex of individuals surveyed. 62 participants nasal samples were confirmed of $S$. aureus infections of which $40(64.5 \%)$ were male and $22(35.5 \%)$ were female.

\section{Discussion}

This surveillance report of Staphylococcal infections underscores the important roles of Gram positive organisms in the hospital and community settings. In this study, prevalence of $230(56.8 \%)$ of S. aureus isolates recovered from the clinical sources and 175 (43.2\%) from the non-clinical setting is in support of earlier finding of Ellingson et al.(2011), who reported that the most commonly encountered hospital acquired infections involved wound, urinary tract, respiratory tract and blood stream. This might be due to the fact that the hospital represents a special 
environment which provides health care to patients and serves as work environment for medical and other staff where organisms may pass from patient to patients or from staff to patients.

Staphylococcal aureus can be acquired in a numbers of ways as the pathogen is ubiquitous and man and other animals are healthy carriers. It could be community acquired especially from the colonized healthy family members (Shiojima et al., 2003) or hospital acquired which could be inform of acquisition from Health care workers during treatment and examination (Stein et al., 2006), and hospital environment which comprises of hospital equipment and materials (Centers for Disease Control and Prevention, 2006). These major sources have been documented as the main source of acquiring staphylococcal infections.

In this finding, different clinical diagnostic cases were studied for possible associated $S$. aureus infections viz; urine, wound, sputum stools and blood. Nasal samples of healthy individuals among food handlers in the community were considered for the non- clinical. The sex and age groups distribution frequency were determined. The analysis of the study reveal that urine $S$. aureus infection in female $(58.6 \%)$ was higher than $(41.4 \%)$ in male, STD cases was about more than doubled of other infections follow by the urinary tract infection (UTI) ; Wound infections in female $(65.5 \%)$ was doubled that of male which was $(34.3 \%)$ and sepsis cases constituted $32.8 \%$; Sputum $S$. aureus infection in female was $56.8 \%$ higher than $43.2 \%$ in male and pulmonary inflammation diagnosis $66.7 \%$ constituted overwhelmingly more than double of other infections ; Stool infections in female $(63.8 \%)$ was higher than $36.2 \%$ in male and diarrhea cases constituted highly of $38.3 \%$; Blood S. aureus associated infection in female $(53.3 \%)$ was higher than $46.7 \%$ in male and bacteremia/ sepsis cases predominated about $63.3 \%$. ( $\mathrm{T}=95 \%$ confidence interval of the difference). This findings corroborated the report of Bennie Lindeque et al. (2008) in the work conducted on prevalence of MRSA among orthopaedic patients at large academic hospital that statistically significant increases in the incidence of MRSA per year occurred in women whereas the increase in MRSA incident was not significant for men. In this report, it is worth noting that incidence rate was the highest in age range 21-30 among urine, wound, sputum and blood samples analyzed which was in agreement with Harptuluoglu et al. (2005) which revealed that the rates of $S$. aureus carriage tends to decrease with age. Diarrheal stools analysis showed an exceptional incident rate of infections which was noticed to be higher among the age range 11-20 and this might likely be associated with infant diarrhea. The limitation of this finding was that the underlying risk factors of individual patients' from which clinical samples were obtained was not known.

Community source $S$. aureus isolates accounted for $43 \%$ of the total isolates from which cell phones and food handlers constituted $15 \%$, and stethoscopes $S$. aureus isolates $13 \%$. In this finding, the carrier rate of $S$. aureus in the nose of apparently healthy individuals among the food handlers in the community was higher among male $(64.5 \%)$ than female $35.5 \%$ ( $\mathrm{T}=95 \%$ confidence interval of the difference). The present finding was at variance to the work conducted by Shanmugan et al. (2008) on the prevalence, antibiogram and characterization of $S$. aureus including MRSA among the healthy staff, and patients from Sri Manakula Vinayagar Medical College and hospital (SMVMCH) Pondicherry, that the carrier rate of $S$. aureus in the nose of male and female healthy carrier among medical students are nearly same which are $24.4 \%$ and $23.5 \%$, respectively. The incident rates of nasal infections among the food handlers surveyed individual was higher among age groups 21-30. Plans are underway to evaluate the relationship between antibiotic use in the hospital and the pattern of antimicrobial resistance observed

Periodic epidemiological studies must be encouraged to determine the interrelatedness of community/ hospital sources of isolates in Nigeria, establishing the pathogens biodiversity to assist infection control measures.

\section{Acknowledgement}

The authors thank the Infectious Control Practitioners and Microbiology Laboratory at OAUTHC for their active participation in this project.

\section{References}

1) Esan, C. O., Famurewa, O., Lin, J. and Shittu A. O. (2009). Characterization of $S$. aureus isolates obtained from health care institution in Ekiti and Ondo state -, South -Western Nigeria. African Journal of Microbiology Research, 3(12) : 3962-968

2) Gorwitz, R. J., Dreanna, K. M., Sigrid, K. M., Geraldine, M., Linda, K., Gregory, E, F., Bette, J. J. And Gorge, K. (2008). Changes in the Prevalence of Nasal Colonization with Staphylococcus aureus in the United States. Journal of Infectious Diseases, 197: 1226-1234

3) Gillet, Y., Jerome, E., Gerald, L. and Francois, V. (2002). Association of necrotizing pneumonia with Panton Valentine Leucocidin- producing $S$. aureus, regardless of methcillin resistance. Clinical Infectious Diseases, 47(7): 985-986.

4) Jerraud, S., Mongel, C. and Thiolouse, J. (2002). Staphylococcal skin infection in children. Clinical Evidence, 7: 692-697.

5) Kikuchi, K. (2003). Genetic basis of neonatal methicillin resistant S.aureus. Pediatric Jounal, 45 (2): 14- 16.

6) Kopp, B. J., Pantwala, A. E. and Norris, C. J. (2004) Clinical and economic analysis of methicillin susceptible and resistant S. aureus infections. Journal of Vector Borne Diseases, 6: 1526644.

7) Klein, E.; David, L. S. And Ramanan, L. (2007). Resistant Staphylococcus aureus. Emergence Infectious Diseases 13: 
Case Profile Analysis on Health- Care Associated Staphylococcal Infections and Community Acquired Sources: Demographic and Clinical Surveillance Study Ile - Ife South Western Nigeria

1840-1946.

8) Klevens, R. M., Morrison, M. A., Nadle, J., Petit, S., Gershman, K; Ray, S., Harrison, L. H., Lynfields, R., Dumyati, G., Townes, J. M., Craig, A. S., Zell, E. R., Fosheim, G. E., McDougal, L. K., Carey, R. B., and Fridkin, S. K. (2006). Invasive methicillin resistant S. aureus infections in the United States, Journal of American Medical Asociation, 298:1763-1771

9) Musser, J. M. and Selander, R. K. (1990). Genetic analysis of natural populations of $S$. aureus in molecular biology of the staphylococci.

10) Klevens, R. M.; Morrison. M. A.; and Fridkin, S. K. (2007). Invasive Methicillin Ressitant Staphylococcus aureus Emergence Infectious Diseases 13:1940-1846.

11) Engemann, J. J., Schmander. K. and Wilson, S. J. (2003) Surgical rate infection due to $S$. aureus among elderly patients Journal of Microbiology, 36: 858-862.

12) Olutiola, P.O., Famurewa, O. and Sonntag, H-G (1991). An Introduction to General Microbiology: Practical Approach. Pp. 126-127.

13) Akindele, A. A., Adewuyi, I. K., Adefioye, O. A., Adedokun, S. A. and Olaolu, A. O. (2010). Antibiogram and Betalactamase production of Staphylococcus aureus isolates from different human clinical specimens in a tertiary health institution in Ile Ife, Nigeria. American - Eurasian Journal of Scietific Research, 5: 230-233.

14) Bennie, L., Jonathan R., Alliison, W. and Jedi, M. (2008). Prevalence of MRSA among Orthopaedic patients at large Academic Hospital. Orthopaedics, 3: 400I .

15) Huda, T., Nair, H., Theodoratou, E., Zgaga L., Fattom, A., E 1 Arifeen, S., Reuben C., Campbell, H. and Rudan, I. (2011). An evaluation of the emerging vaccines and immunotherapy against staphylococcal pneumonia in Children. Biomedical Public Health, 11: S27-30

16) CDC (2006). National Centres for Chronic Diseases prevention and health http://www.cdc.gov/scientific htm. Retrieved 2009. 08.10

17) Ellingson, K., Robert, R. M., Rajiv, J., David, K. and Candace, C. (2011). Sustained reduction in the clinical incidence of methicillin resistant $S$. aureus colonization or infection associated with a multi- faceted infection control intervensions. Journal of Infection Control and Hospital Epidemiology, 532 : 1-8.

18) Harptuluoglu, U., Ugel, E. and Sahin, I. (2005). Nasopharyngeal aerobic bacterial flora and $S$. aureus nasal carriage in deaf children. International Journal of pediatric. Otorhinolaryngology, 69: 69-74.

19) Shiojima, T., Ohki, Y, Nako, Y., Morikawa, A., Okubo, T. and Iyobe, S (2003). Immediate control of a methicillinresistant Staphylococcus aureus outbreak in a neonatal intensive care unit. Journal of Infection Chemotherapy, (3): 243-247

20) Shopsin, B. and Kreiswirth, B.N. (2001). Molecular epidemiology of met-resistanct Staphylococcus aureus. Emerging Infectious Diseases, 7(2): 323-326.

21) Lowy, F.D. (1998). S. aureus infection. New England of Journal of Medicine 339: 520-525.

22) Lodise, T. P. and McKinnon, P. S. (2005). Diagnostic Microbiology. Infectious Diseases, 52: 113-122.

23) Nixon, M., Jackson, B., Varghese, P., Jenkins, D. and Taylor, G. (2006). Rate of infection and colonization by methicillin resistant $S$. aureus. Journal of Clinical Microbiology, 88 (6): 812-817. 